\title{
Diurnal variation of non-specular meteor trails
}

\author{
J. Hinrichs ${ }^{1}$, L. P. Dyrud ${ }^{1}$, and J. Urbina ${ }^{2}$ \\ ${ }^{1}$ Center for Remote Sensing, Inc., Fairfax, VA, USA \\ ${ }^{2}$ Communications and Space, Sciences Laboratory, Pennsylvania State University, University Park, PA, USA
}

Received: 1 October 2008 - Revised: 3 March 2009 - Accepted: 3 March 2009 - Published: 4 May 2009

\begin{abstract}
We present results of simulated radar observations of meteor trails in an effort to show how non-specular meteor trails are expected to vary as a function of a number of key atmospheric, ionospheric and meteoroid parameters. This paper identifies which geophysical sources effect the variability in non-specular trail radar observations, and provides an approach that uses some of these parameter dependencies to determine meteoroid and atmospheric properties based upon the radar meteor observations. The numerical model used follows meteor evolution from ablation and ionization to head echo plasma generation and through formation of field aligned irregularities (FAI). Our main finding is that non-specular meteor trail duration is highly sensitive to the presence of lower thermospheric winds or electric fields and the background ionospheric electron density. In an effort to make key predictions we present the first results of how the same meteoroid is expected to produce dramatically different meteor trails as a function of location and local time. For example, we show that mid-latitude trail durations are often shorter lasting than equatorial trail observations because of the difference in mid-latitude wind speed and equatorial drift speed. The simulated trails also account for observations showing that equatorial nighttime non-specular meteor trails last significantly longer and are observed more often than daytime trails.
\end{abstract}

Keywords. Ionosphere (Ionospheric irregularities; Plasma waves and instabilities) - Radio science (Waves in plasma)

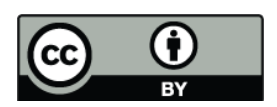

Correspondence to: L. P. Dyrud

(ldyrud@cfrsi.com)

\section{Introduction}

The daily occurrence of billions of meteor trails in the Earth's upper atmosphere present a powerful opportunity to use remote sensing tools to better understand the meteoroids that produced them and the atmosphere and ionosphere in which their trails occur. One of the most promising tools employed in this endeavor are high-power-large-aperture (HPLA) radars. Such radars routinely observe two distinct types of meteor echoes, head echoes and non-specular meteor trails. Head echoes are the radar reflection from targets with short durations, usually less than 1 millisecond at a given range, and moving at apparent meteoroid velocities (Close et al., 2002; Janches et al., 2000; Mathews et al., 2001; Chau and Galindo, 2008; Dyrud et al.. 2008). When radars are pointed perpendicular to the magnetic field, head echoes are often, but not always, followed by echoes lasting seconds to minutes (Dyrud et al., 2005; Zhou et al., 2001). Because these echoes occur simultaneously over multiple radar range gates, the term non-specular echoes has been adopted by many authors in order to differentiate them from the meteor echoes from specular meteor radars, which require a trail to align perpendicular to the radar beam (Ceplecha et al., 1998; Cervera and Elford, 2004). The focus of this paper is to provide a theoretical model that predicts and describes the essential variation of non-specular trail observations, including when (local time, and trail duration) and where (altitude ranges of echoes). This analysis is conducted in light of our current view that non-specular echoes result from radar reflections from field aligned irregularities produced by plasma instability (Dyrud et al., 2007). We continue with a review of some of the reported observations of non-specular meteor trails. 


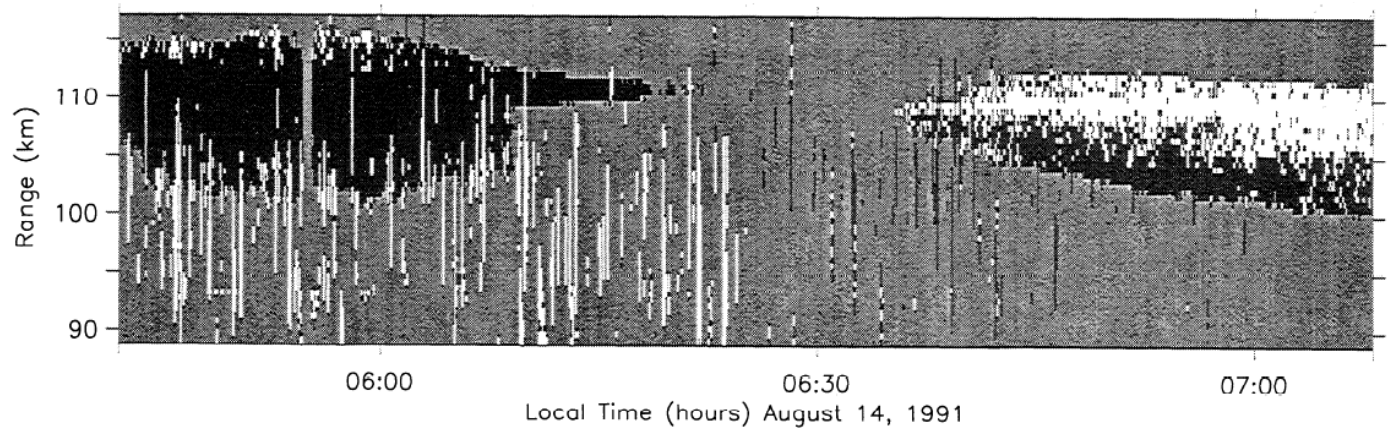

Fig. 1. The extreme change of meteor echo occurrence and durations observed before and after dawn (reproduced from Chapin and Kudeki, 1994a). Over 125 meteor echoes are observed from the start of the image until an abrupt break in meteor reflection occurrence near sunrise at 06:20 LT(after which only $\sim 20$ trails are observed).

\section{Review of observations of non-specular trails}

While the data set on non-specular meteor trails remain sparse in terms of geographical and local time coverage, several observational trends have been reported in the literature. Yet, the work presented here, and the model we have constructed, is critical for placing meteor data from individual sites in context of a global meteor flux into a local atmosphere and ionosphere. More succinctly, we are interested in understanding how a meteoroid of a given mass, velocity, and entry angle will produce different radar signatures at different geographical locations and different local times. We continue with a review of some of the relevant non-specular trail observations that have been published in recent years.

Chapin and Kudeki (1994a, b) published some of the first observations of non-specular trails from the Jicamarca $50 \mathrm{MHz}$ radar. While it was not the focus of their papers, the difference in meteor trail occurrence and duration before and after sunrise was clearly shown in one of their figures, which we have reproduced here as Fig. 1. This figure shows two distinct periods of non-specular trail observations; the first half contains over 125 trail echoes before sunrise near 06:20 LT, followed by an abrupt decrease in the number trails observed. After 06:20 only 20 meteor echoes are seen through out the second half of the figure. The authors also noted that throughout the observations that non-specular trail echoes extended from 90 to $117 \mathrm{~km}$ altitude, and that meteor trails were centered at $97 \mathrm{~km}$. They also pointed out what they called the existence of a "fainter third electrojet layer" at $97 \mathrm{~km}$ altitude. In this article we shall focus on the diurnal variation, and will address the issue of altitude variability in an upcoming publication.

Recently, Oppenheim et al. (2008) drew specific attention to the diurnal variability of non-specular echoes at equatorial latitudes. They presented observations before and after sunrise demonstrating a stark difference in the number of head echoes with corresponding non-specular trails. Before dawn, 341 non-specular trails were observed for 1288 head echoes in a 20 min period, while only 81 trails for 1240 head echoes were observed in $20 \mathrm{~min}$ after dawn. They suggested that this was evidence of a previously published theory by Dimant and Oppenheim $(2006 \mathrm{a}, \mathrm{b})$ that predicted stronger zeroth order ambipolar fields during night, and therefore an enhanced driver for instabilities. In contrast, we provide an alternative explanation for this day night variability, which involves not just background electron density but the presence of background electric fields or winds that drive polarization fields within the meteor trail.

Dyrud et al. (2002) published simulations and some observations of non-specular trials from the ALTAIR radar which is just off of the geomagnetic equator. This paper showed that of 16 head echo-trail pairs that were examined, all of the trails were confined to a more narrow altitude range than were the head echoes. This paper provided evidence that the altitudinal profile of atmospheric and ionospheric parameters could dictate the stability or instability of portions of the meteor trial column.

Dyrud et al. (2005) published seasonal and diurnal variations of specular and non-specular echoes from the Coquii II NASA rocket campaign over Puerto Rico, together with head echo measurements from the nearby Arecibo Radar. While the non-specular trail data sets only spanned $12 \mathrm{~h}$ from dusk until dawn, one thing was clear from the observations. In the few occasions that observations extended $1 \mathrm{~h}$ past dawn, there was approximately a factor of 2 decrease in non-specular trail occurrence rate, which is consistent with, but more modest than the equatorial observations reported by Oppenheim et al. (2008). The decrease in non specular trail duration and the total number of non-specular trail observations from before to after sunrise can be seen when comparing Figs. 2 and 3, which are from the same Coquii II data set analyzed in Dyrud et al. (2005), and the reader is referred to Urbina et al. (2000) for additional information regarding this campaign and data.

Dyrud et al. (2007) recapitulated observations from Chapin and Kudeki (1994b) and modeled some of those 


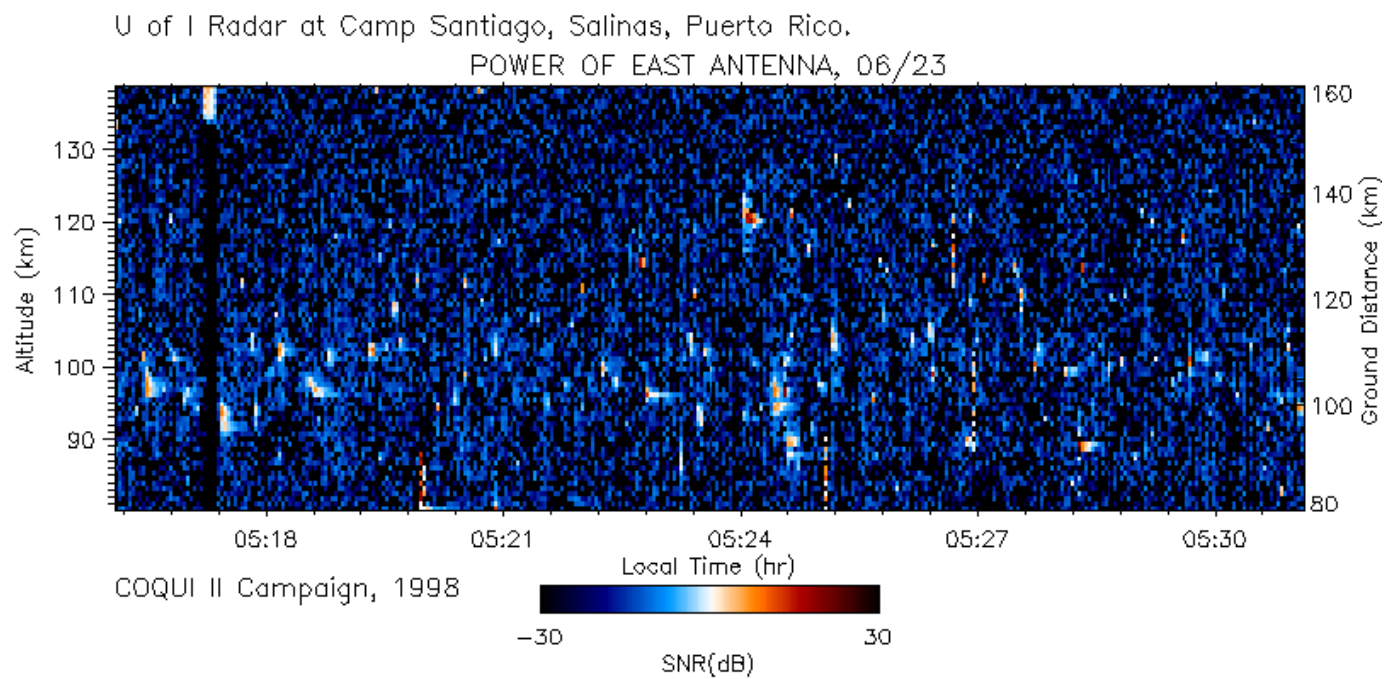

Fig. 2. RTI images of meteor observations just before sunrise at 05:49 AST, on 23 June 1998 during the Coqui II campaign see Urbina et al. (2000) for more information on the radar and campaign. Each bright spot extended in multiple range bins and for multiple time bins represents a non-specular meteor trail.

U of I Radar at Camp Santiago, Salinas, Puerto Rico.

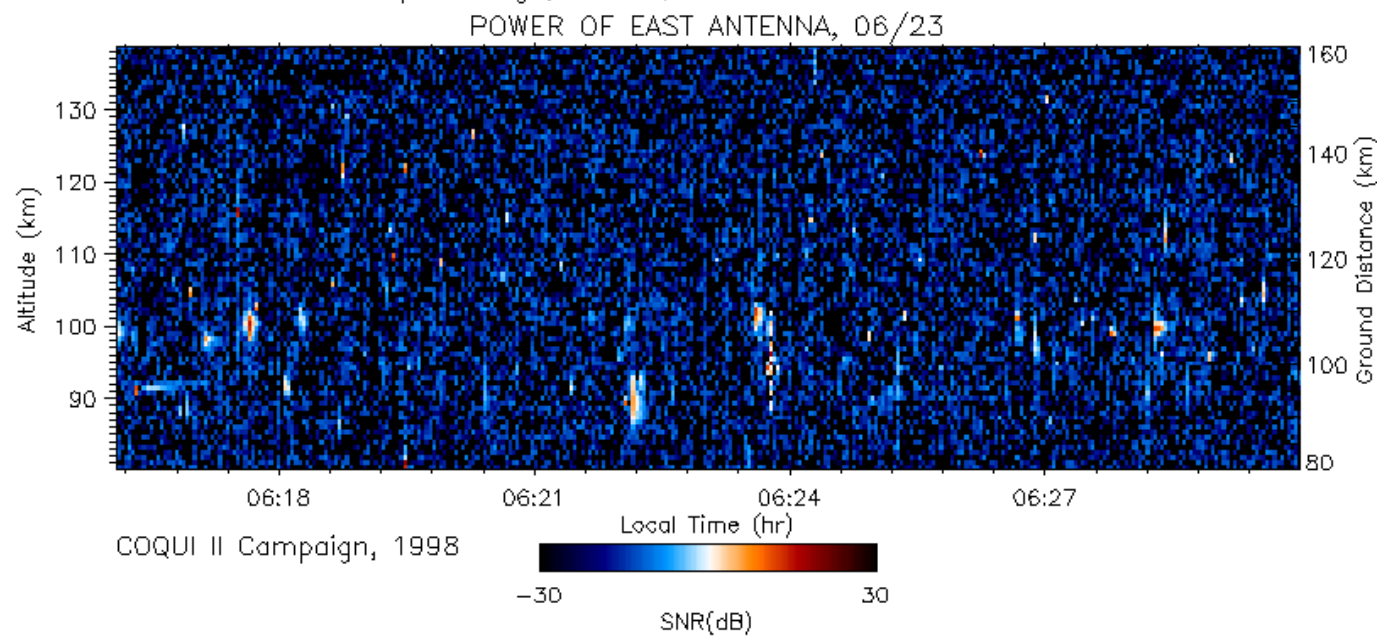

Fig. 3. Meteor observations, in the same format as Fig. 1, but shortly after sunrise, far fewer and slightly shorter duration meteors were detected.

observations to show that long duration meteor trails, of the order of minutes, are likely caused by milligram and larger meteoroids in the presence of a polarizing electrojet, and that shorter duration (seconds) meteor trails resulted from microgram sized meteoroids. They also showed that meteor trail duration was significantly reduced when the background electron density was increased by two orders of magnitude. Further, the model results presented in this paper are entirely based on the model described in Dyrud et al. (2007) and the reader is directed there for a more detailed description of the modeling methodology.
Zhou et al. (2001) presented observations of head echoes and non-specular trails from the MU $50 \mathrm{MHz}$ radar in Japan $\left(34.9^{\prime \prime} \mathrm{N}, 136.1^{\prime \prime} \mathrm{E}\right)$, which is considered at mid-latitude. This experiment was conducted with the radar pointing both perpendicular, and off-perpendicular to the geomagnetic field. Their results showed that there are far more nonspecular trails observed when the radar pointed perpendicular to the magnetic field then when it was pointed off. They also noted that the essentially all head echoes had a corresponding non-specular trail in the perpendicular to $\boldsymbol{B}$ geometry, while the off-perpendicular observations had essentially no trails, but similar counts of head echoes. They reported 


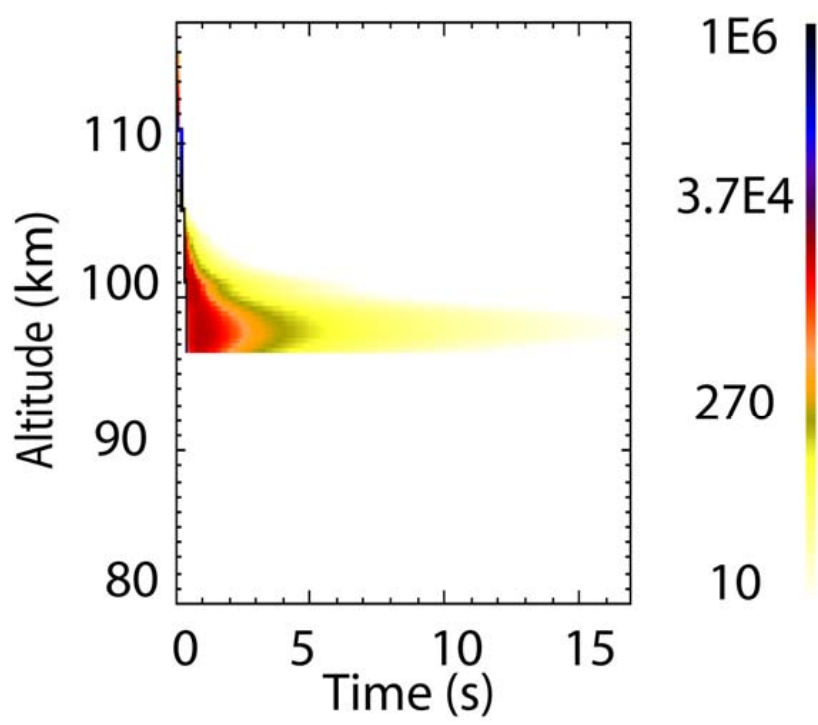

Fig. 4. $17 \mathrm{~s}$ RTI simulation using Jicamarca conditions for 04:00 a.m. LT, one 1 June. The meteoroid mass is $0.01 \mathrm{mg}$, traveling at a velocity of $55 \mathrm{~km} / \mathrm{s}$, composed of an atomic mass of $25 \mathrm{AMU}$.

that trails extended from $84-100 \mathrm{~km}$ altitude, but their data were collected from 00:00 to 08:30 LT over 4 nights, and they made no comment on pre and post sunrise differences. These results cemented the view that non-specular echoes result from plasma instability induced field aligned irregularities (FAI).

Malhotra et al. (2007) presented multi static observations of non-specular meteor trials using the Jicamarca radar and an additional receiving station at Carapongo, approximately $5 \mathrm{~km}$ away. Their results showed that non-specular trail duration observations are unambiguously aspect sensitive, with the longest lasting echoes coming from the perpendicular to $\boldsymbol{B}$ locus of points within the beam. It is worth noting that the simulations presented here do not take observing geometry into account, but are focused on addressing what the inherent reflectivity of a non-specular trail is as a function of aeronomy and meteor parameters.

In order to understand the effect that electron density and other factors such as winds and electro-jet drifts have on nonspecular trails, a computer program was used to simulate radar observations of meteor head echoes and non-specular trails under a variety of conditions. We continue with a description of theses simulations and the results, which are focused on predictions for diurnal trends in non-specular meteor trails.

\section{Description of model used for simulations}

We constructed a model of the evolution of an individual meteor from atmospheric entry to trail instability and diffusion. This model was used to make a computer program that sim- ulates artificial radar range-time-intensity-images (RTI) for comparison with facilities like Jicamarca and other coherent radars. The model has been described in previous papers by Dyrud et al. (2005, 2007), and we simply summarize its description here and discuss our recent incorporation of climatological models for the atmospheric and ionospheric drivers and background conditions

This program simulates meteoroid entry into the atmosphere, including ablation, ionization, thermal expansion and plasma stability based upon meteor Farley-Buneman Gradient-Drift (FBGD) instability (Dyrud, 2001, 2002; Oppenheim, 2000, 2004a, b). The model results are a prediction of the expected head echo and non-specular trail for a given set of meteoroid and atmospheric/ionospheric parameters, with the results displayed in simulated RTI images similar to those produced by radar. The RTI simulator retrieves location and time specific ionospheric and atmospheric data from three main climatological models, CIRA, IRI2000, and the Horizontal Wind Model (HWM) (these models were obtained from and are described at http://ccmc.gsfc.nasa.gov/ modelweb/models_home.html).

The parameters we require from these models include electron density, atmospheric mass density, neutral temperature and wind speed, and from these we also derive ion and electron collision frequencies based upon Banks and Kockarts (1972), for a given location and time. This inclusion of climatological models allows us to examine how non-specular trails are expected to vary as a function of the different background parameters occurring at various locations and local times. We also are able to simulate equatorial meteor trails using a separate drift model instead of HWM, and derived Cowling profile, which allows us to address the unique conditions at Jicamarca where a majority of the existing data on non-specular trails has been taken.

Figure 4 provides an example of an artificial radar RTI meteor simulation produced by this model. The color bar represents meteor line density in units of electron per micron for the thin head echo trace, while the non-specular trail color indicates the trails FBGD growth rate in units of inverse seconds. In order to present the statistical results shown in the following section, the simulation has been inserted into loops that generate meteor trails under the different conditions that are dictated by the climatological models, and then measures the duration of each non-specular trail.

\section{Diurnal variability of meteor trail duration}

The first parameter dependency we examine is that of latitude. In particular we were interested in comparisons between trail durations at mid-latitudes, where a number of coherent radar experiments have been undertaken, and those at equatorial latitudes where numerous observations using the Jicamarca radar have been conducted. The primary expected difference between mid-latitude meteor observations 


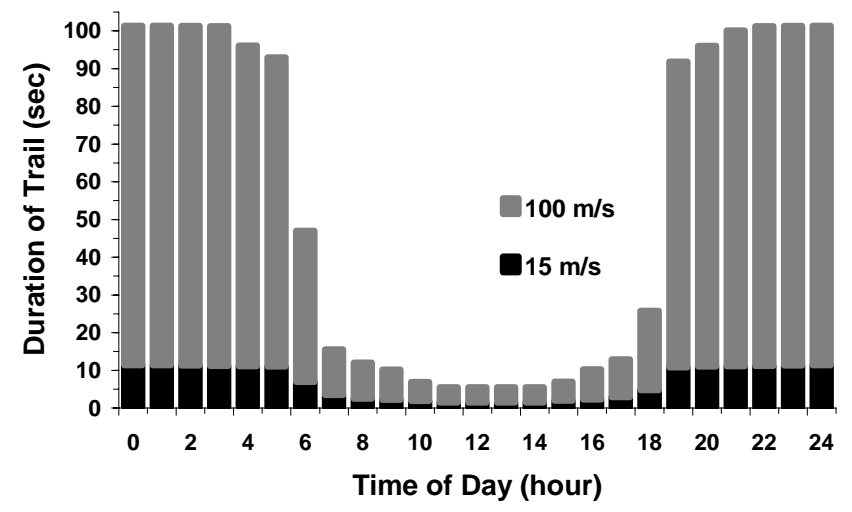

Fig. 5. Effect of the diurnal variation of ionospheric electron density on a $0.01 \mathrm{mg}$ meteor's non-specular trail duration, in seconds, for two drifts speeds $(15 \mathrm{~m} / \mathrm{s}$ and $100 \mathrm{~m} / \mathrm{s})$. This figure shows the differences in equatorial meteor observations $(100 \mathrm{~m} / \mathrm{s})$ and midlatitude observations $(15 \mathrm{~m} / \mathrm{s})$. The model run was for a $0.01 \mathrm{mg}$ meteoroid at a velocity of $50 \mathrm{~km} / \mathrm{s}$ with an atomic composition of 30 AMU.

and equatorial meteor observations is that the ionospheric drift speed at the equator is generally much faster than the polarization electric field inducing horizontal winds at midlatitudes. Further the magnetic field strength at equatorial latitudes is also approximately $50 \%$ stronger, which causes subtle effects via the electron cyclotron frequency.

The difference in non-specular trail duration as a function of background wind velocity or drift speed was simulated by testing the same meteor at two different drift speeds for each hour of the day. This allows us to isolate the effect that background drift speed in conjunction with diurnal differences in electron density has on trail duration. It is important to point out here that the drift speed used in the model, is the speed for the component of drift that is perpendicular to both the meteor trail axis and the geomagnetic field. A nominal equatorial-like drift speed was set at $100 \mathrm{~m} / \mathrm{s}$, while a mid-latitude-like wind speed was set at $15 \mathrm{~m} / \mathrm{s}$. The results of these simulations for a $0.01 \mathrm{mg}$ meteoroid at a velocity of $50 \mathrm{~km} / \mathrm{s}$ with an atomic composition of $30 \mathrm{AMU}$, are depicted in Fig. 5. This figure shows that trails immersed in a $100 \mathrm{~m} / \mathrm{s}$ wind were significantly longer lasting than trails in a $15 \mathrm{~m} / \mathrm{s}$ wind. This simulation also shows the effect that the diurnal cycle of ionospheric electron density has on nonspecular trail duration. Night time meteor trail duration last the longest due to the decrease in background electron density which will increase trail polarization electric fields as described in Dyrud et al. (2007).

The conclusion from Fig. 5 is as follows: it is clearly seen that the diurnal variation for non-specular trails is far more pronounced for fast cross-trail drift speeds than it is for slower speeds. These results provide an initial explanation for why mid-latitude day-night differences for non-specular trails (as presented in Figs. 2 and 3) are less pronounced than
Vetrical Drift as a Time of Day at Jicamarca

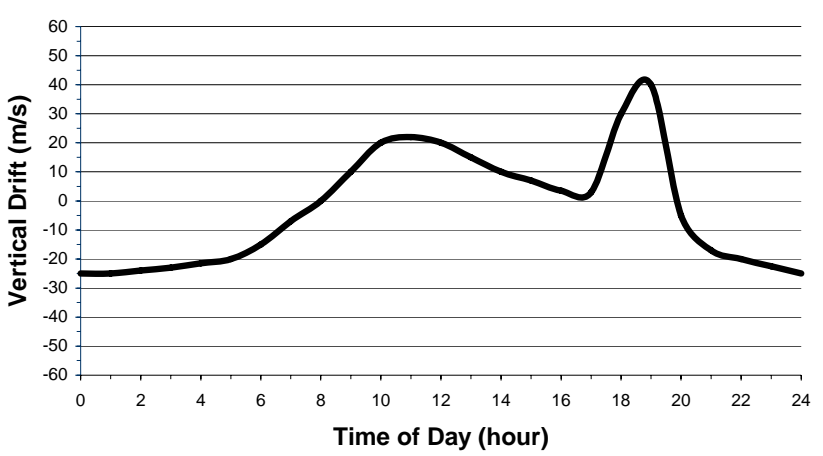

Fig. 6. Average vertical drift speed model over Jicamarca obtained from Fejer and Scherliess (2001). This data is used to drive the meteor simulations as a function of time. The vertical drift data was multiplied by nominal cowling and geometrical factor of 10 in order to approximate the drift speed perpendicular to both B and the meteor trail. When drift speeds are approach zero the model predicts no long duration trails are produced.

those at the equatorial latitudes as presented by Oppenheim et al. (2008), and in Fig. 1.

While the results of Fig. 5 isolated the effects of drift speed, we now present results that attempt to model the diurnal variation of a number of relavent drivers. First, zonal electrojet drifts must be taken into account. We approximated zonal drift by modeling the average vertical drift as a function of local time from Fejer and Scherliess (2001), which is shown in Fig. 6. This vertical drift is multiplied it by a cowling/geometry factor of 10 , providing an approximate cross-meteor trail drift speed for an average day at the equator. The second factor that must be considered is a nominal geocentric meteoroid velocity as a function of local time. Fentzke and Janches (2008) have investigated the sporadic meteoroid flux to show that the flux is aligned with several nominal sources when viewed in the heliocentric frame, and Chau et al. (2007) has specifically examined these sources using for the Jicamarca radar. The radar view of these sources changes as the earth rotates and the beam will point in the direction of Earth's orbit around the sun (morning) or away (dusk). A nominal night time micrometeoroid meteor velocity is $\sim 30 \mathrm{~km} / \mathrm{s}$ and independent modeling (not shown in this paper) has shown this as a near ideal speed for long duration meteor trails. This is because slower meteoroids penetrate lower in altitude where diffusion rates are slower and polarization electric fields are stronger (Dyrud et al., 2007). This result contributes to why long duration meteor trails are dominantly observed at night. The diurnal velocity profile used in our simulation can be seen in Fig. 7. While this is an approximate profile we have used model results for nominal zenith angle and speed for the Jicamarca location from the Fentzke and Janches (2008) model, and find similar results to those presented here. 


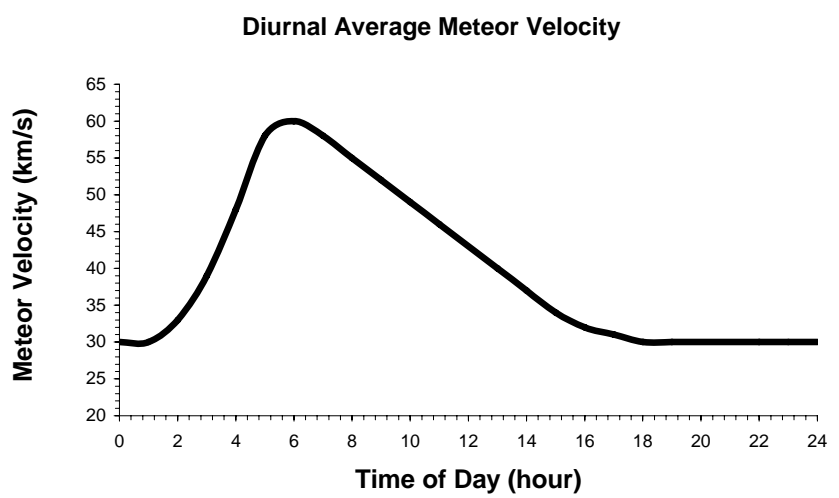

Fig. 7. Simplified model of the nominal diurnal variation of micrometeoroid velocity used in the $24 \mathrm{~h}$ simulation presented in Fig. 8. Note that a night time meteor velocity of about $30 \mathrm{~km} / \mathrm{s}$ is a near ideal speed for generating long duration meteor trails, a contributing factor to the increase in long duration trails at night.

After examination of the factors influencing meteor trail duration, it is now possible to simulate and analyze trail duration at the equator over $24 \mathrm{~h}$. As discussed above, the simulation we conducted uses climatological models to approximate the diurnal change in the environment and drivers, these include the electron density from IRI, atmospheric density and temperature from CIRA, zonal drift speed from Fejer and Scherliess (2001), and a simplified meteor velocity cycle to predict non-specular trail duration at Jicamarca. Figure 8 shows the results from a $24 \mathrm{~h}$ simulation of a 1 microgram meteor with an atomic mass of $30 \mathrm{AMU}$. This figure shows that once all these models for the environment and drivers are included the results are a dramatic diurnal variability in predicted non-specular trail duration. The gross features in this figure are clearly associated with the diurnal effect of ionization. For daytime meteors, from 05:00 to 17:00 LT, predicted meteor duration is short, around $1 \mathrm{~s}$ or less. During the evening and into night time when the electron density becomes less dense, zonal drift speed plays a major role in determining trail duration. Zonal drift speed's effect on trail duration is most easily seen between 18:00 and 20:00 h. During this period there is a large jump in trail duration from a trail duration lasting $3 \mathrm{~s}$, up to a $27 \mathrm{~s}$ duration and back to $3 \mathrm{~s}$ again a few hours later. This jump in meteor trail duration is due to an extreme increase and decrease in drift speed seen at sunset called pre-reversal enhancement (Fejer and Scherliess, 2001). The effect that the nominal change in meteor velocity has on meteor trail duration is visible in Fig. 8. Based on the diurnal velocity model, our average nighttime meteor velocity is simulated at $30 \mathrm{~km} / \mathrm{s}$, which is ideal for long duration trails because, faster meteors will ablate higher and not penetrate below $100 \mathrm{~km}$ altitude, where trail durations become longer due increasing polarization electric field, the Cowling profile of the electrojet electric field and reduced diffusion rates (Dyrud et al., 2007). From 02:00 until sunrise the av-

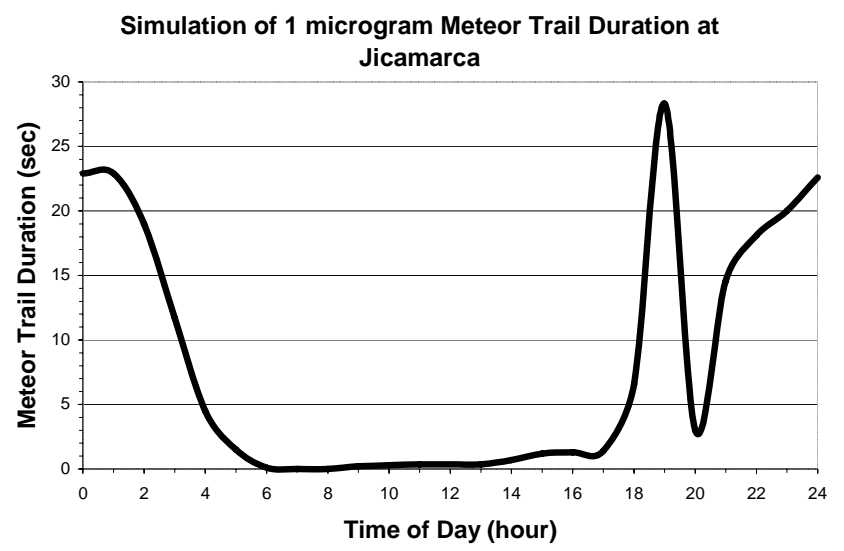

Fig. 8. Simulated non-specular trail durations produced by 1 microgram meteoroids as a function of time of day. This simulation uses; the diurnal electron density of the ionosphere, zonal drift speed, and the meteor velocity cycle to predict non-specular trail duration at Jicamarca. The electron density of the ionosphere has a very apparent effect on duration, during the daytime the predicted trail duration is $1-2 \mathrm{~s}$. The electron density has the strongest affect on non-specular trail duration. During the evening and into night time when the electron density becomes less dense, zonal drift speed plays a major role in determining trail duration. Zonal drift speed's effect on trail duration is most easily seen between 18:00 and 20:00 h. During this period there is a large jump in trail duration from a $3 \mathrm{~s}$ duration up to a $27 \mathrm{~s}$ and back down again during the prereversal enhancement.

erage meteor velocity increases, meteor trail duration shortens. Velocity effect on trail duration can also be seen from 14:00 to 16:00 LT. At this time there is a slight increase in trail duration even though electron density is still at its daytime density, and zonal drift speeds are relatively slow. This increase in trail duration is due to meteor velocity slowly decreasing from sunrise to sunset and approaching longer trail producing velocities, and by 14:00 LT, meteor velocity begins to approach a more ideal velocity for longer duration trails.

\section{Conclusions}

This paper presents a $24 \mathrm{~h}$ simulation of equatorial meteor duration in order to understand the diurnal changes that effect meteor duration. This simulation used $24 \mathrm{~h}$ data for the ionosphere's electron density, a diurnal nominal meteor velocity model, and an average diurnal vertical drift model. Our simulations show a significant diurnal difference in non-specular trail duration. Daytime meteor trail durations are short and at times no trail is produced, because high electron density and faster nominal meteor speeds are less conducive to long duration trails. These results are further affected by lower zonal drift speeds shortly after sunrise and before sunset. Nighttime meteor trails are much longer in duration. This is because electron density is at its lowest at night and the 
average meteor velocity slows down to a velocity that produces longer duration trails. Zonal drift speeds also show a more prominent effect on trail durations during nighttime as well. The pre-reversal enhancement influence on the durations shown in Fig. 8 is the most obvious example of effect zonal drift on trail duration.

This paper provided evidence to explain why long duration meteors are most common at night, why significantly fewer non-specular meteor trails are observed during the day, and provides a $24 \mathrm{~h}$ model for equatorial meteor trail durations. We conclude by pointing out that while our discussion of trail plasma stability in this paper is centered on the observational phenomena of non-specular trails, we are essentially modeling the duration of plasma instabilities within meteor trails. Therefore, these results will be of interest to any researcher studying meteor trails and the effects that the development of plasma turbulence may have.

Acknowledgements. Lars Dyrud's and Jason Hinrichs' work was supported by NSF grants ATM-0613706 and ATM-0638912, and Julio Urbina's work was supported by NSF grants ATM- 0638624 and ATM- 0457156.

Topical Editor K. Kauristie thanks J. Fentzke and J. Sahr for their help in evaluating this paper.

\section{References}

Banks, P. M. and Kockarts, G.: Aeronomy: Part A, Chapter 9, Academic Press, 1972.

Ceplecha, Z., Borovicka, J., Elford, W. G., Revelle, D. O., Hawkes, R. L., Porubcan, V., and Simek, M.: Meteor phenomena and bodies, Space Sci. Rev. 84, 327-471, 1998.

Cervera, M. A. and Elford, W. G.: The meteor radar response function: Theory and application to narrow beam MST radar, Planet. Space Sci., 52, 591-602, 2004.

Chapin, E. and Kudeki, E.: Radar interferometric imaging studies of long duration meteor echo observed at Jicamarca, J. Geophys. Res., 99, 8937-8949, 1994a.

Chapin, E. and Kudeki, E.: Plasma-wave excitation on meteor trails in the equatorial electrojet, Geophys. Res. Lett., 21, 2433-2436, 1994b.

Close, S., Oppenheim, M., Hunt, S., and Dyrud, L.: Scattering characteristics of high-resolution meteor head echoes detected at multiple frequencies, J. Geophys. Res. (Space Physics), 107(A10), SIA 9-1, 1295, doi:10.1029/2002JA009253, 2002.

Chau, J. L., Woodman, R. F., and Galindo, F.: Sporadic meteor sources as observed by the Jicamarca high-power large-aperture VHF radar, Icarus, 188(1), 162-174, 2007.
Chau, J. L. and Galindo, F.: First definitive observations of meteor shower particles using a high-power large-aperture radar, Icarus, 194(1), 23-29, 2008.

Dimant, Y. S. and Oppenheim, M. M.: Meteor trail diffusion and fields: 2. Analytical theory, J. Geophys. Res., 111, A12313, doi:10.1029/2006JA011798, 2008a.

Dimant, Y. S. and Oppenheim, M. M.: Meteor trail diffusion and fields: 1. Simulations, J. Geophys. Res., 111, A12312, doi:10.1029/2006JA011797, 2008b.

Dyrud, L. P., Oppenheim, M. M., Close, S., and Hunt, S.: Interpretation of non-specular radar meteor trails, Geophys. Res. Lett., 29(21), 2012, doi:10.1029/2002GL015953, 2002.

Dyrud, L. P., Denney, K., Urbina, J., Janches, D., Kudeki, E., and Franke, S.: The meteor flux: it depends how you look, Earth, Moon Planets, 95, 89-100, 2005.

Dyrud, L. P., Kudeki, E., and Oppenheim, M. M.: Modeling long duration meteor trails, J. Geophys. Res., 112(A12), A12307, doi:10.1029/2007JA012692, 2007.

Dyrud, L. P. and Janches, D.: Modeling the meteor head echo using Arecibo radar observations, J. Atmos. Solar-Terr. Phys., 70, 1621-1632, 2008.

Janches, D., Mathews, J. D., Meisel, D. D., and Zhou, Q.-H.: Micrometeor Observations Using the Arecibo $430 \mathrm{MHz}$ Radar, Icarus, 145, 53-63, 2000.

Fejer, B. G. and Scherliess, L.: On the variability of equatorial F-region vertical plasma drifts, J. Atmos. Solar-Terr. Phys., 63, 893-897, 2001.

Fentzke, J. T. and Janches, D.: A semi-empirical model of the contribution from sporadic meteoroid sources on the meteor input function in the MLT observed at Arecibo, J. Geophys. Res., 113, A03304, doi:10.1029/2007JA012531, 2008.

Malhotra, A., Mathews, J. D., and Urbina, J.: Multi-static, common volume radar observations of meteors at Jicamarca, Geophys. Res. Lett., 34, L24103, doi:10.1029/2007GL032104, 2007.

Mathews, J. D., Janches, D., Meisel, D. D., and Zhou, Q. H.: The micrometeoroid mass flux into the upper atmosphere: Arecibo results and a comparison with prior estimates, Geophys. Res. Lett., 28, 1929-1932, 2001.

Oppenheim, M. M., Sugar, G., Bass, E., Dimant, Y. S., and Chau, J.: Day to night variation in meteor trail measurements: Evidence for a new theory of plasma trail evolution, Geophys. Res. Lett., 35, L03102, doi:10.1029/2007GL032347, 2008.

Urbina, J., Kudeki, E., Franke, S. J., González, S., Zhou, Q., and Collins, S. C.: $50 \mathrm{MHz}$ radar observations of mid-latitude Eregion irregularities at Camp Santiago, Puerto Rico, Geophys. Res. Lett., 27, 2853-2856, 2000.

Zhou, Q. H., Mathews, J. D., and Nakamura, T.: Implications of Meteor Observations by the MU Radar, Geophys. Res. Lett., 28(7), 1399-1402, 2001. 